\title{
Contemporary Japanese Migration Process in Spain: Cultural Boundaries and Social Networks
}

\author{
Jordi Martinez-Callaghan, Marta Gil-Lacruz, Ana Gil-Lacruz \\ University of Saragossa, Saragossa, Spain
}

\begin{abstract}
The host society plays a fundamental role in the development of both the sense of belonging and social networks, especially in the field of international migration. The sample of this study is made up of 44 Japanese residents in Spain. Information was obtained using in-depth interviews. The results show that the new migratory strategies of the Japanese favour the construction of new social networks with multiethnic enclaves. This, in turn, contributes to the favourable development of a sense of belonging to the host society. Furthermore, five key variables were identified in this process: (a) Spanish family and friends; (b) interest in some specific aspects of the host society prior to the settling down phase; (c) workplace environment; (d) ethnic heterogeneity and use of support networks; and (e) level of proficiency in Spanish.
\end{abstract}

Keywords: sense of belonging, social networks, Japanese community

\section{Introduction}

The relationship between flexibility and fluidity of migration waves in the era of globalization leads us to question how a sense of belonging arises, especially when concepts, such as home, family, or nation, have physical limits which are difficult to determine (Sasaki, 2004).

As proposed by Ahnellen, Suyemoto, and Carter (2006), the sense of belonging is a complex and subjective process that is forged through life experiences and constant negotiation between the individual and his/her surrounding environment. Magat (1999), using a comparative study of Japanese and Israeli immigrants in Canada, highlighted two key elements in developing a sense of belonging in a foreign country. Firstly, she pointed out that the ethnic composition of social networks can facilitate or hinder the adaptation process; and secondly, she believed that the opportunities for personal development, offered by the host society, is another factor that determines this process during the post-migration phase.

In the field of international migration, the study of second-generation immigrants can be considered a good example of the constant negotiation between the cultural baggage inherited from the home country, and that acquired in the host society (Ariza, 2002; Gualda Caballero, 2004; Lueck \& Wilson, 2010). In the case of Asian groups in the West, because of the magnitude of culture shock and their settling down process, which is characterised by ethnic isolation (Camarero Rioja \& Garcia Borrego, 2004; Beltrán, 2005), a tendency to develop a sense of belonging, founded on exclusion or opposition to other groups, has been identified (Machimura, 2003).

Jordi Martinez-Callaghan, Ph.D., associate researcher, Department of Social Work, University of Saragossa.

Marta Gil-Lacruz, Ph.D., professor, Department of Psychology, University of Saragossa.

Ana Gil-Lacruz, Ph.D., professor, Department of Economics, University of Saragossa. 
Regarding studies of second- and third- generation Japanese in South America and the United States, Suzuki (2006), Green (2008), and Takamori (2010) stressed that, despite the apparent impenetrability of these ethnic enclaves, these communities have gradually adopted certain habits and behaviour patterns of the host society, which has led to the birth of a new hybrid identity and a dual feeling of belonging.

As pointed out by White, Hwa-Seo, and Pierre (2006) and Martínez-Callaghan and Gil-Lacruz (2011), the Japanese model of migration to Europe has evolved in recent decades. While until the early 1990s, the migration objective was closely linked to economic interests, with entry to the new millennium, there has been an increase in the number of Japanese who choose Spain as a destination, motivated by more personal interests, such as the search for a new lifestyle or interest in certain cultural aspects of the host society. Fujita (2009) called this new migration trend "cultural immigration", because one of its peculiarities is the expansion of social and cultural capital before and during the settling down phase.

One of the key elements in this transition of migration patterns is that migrants are unhappy with certain aspects of the society of origin. The difficulties that Japanese society imposes on women's access to certain jobs (Ono \& Piper, 2004) or the acquired and assigned roles in areas, such as family or work (Ashikari, 2003; Rindfuss, Bumpass, Choe Kim, \& Tsuya, 2004), contrast with the social imaginary of countries like Spain and promote a feeling of belonging to the country of destination even before starting the migration project.

Burgess (2012) and Goodman, Peach, Ayumi, and White (2003) considered that, in Japan as well as in Japanese communities in the West, increasing interaction between Japanese and foreigners is causing changes in both rigid Japanese social norms and the Japanese feeling of national identity. For these authors, the people who belong to social networks with multiethnic enclaves are important agents of social change in as far as new guidelines and resulting values are leading to a new idea of what it is to be Japanese, and therefore, a new sense of belonging to their community.

The research presented here aims to identify those variables which are most relevant to members of the Japanese community when negotiating their new identity and sense of belonging in relation to the host society during their migration project. Special attention is given to those aspects which have influenced the process of adopting this new identity, the composition of social networks, the social imaginary, and behaviour patterns and values of both societies. With this aim in mind, the starting point of the study is based on an ecological perspective (Bronfenbrenner, 1976), which enables identification of the role of each of the systems (macro, meso, and micro) to which informants belong, and on the grounded theory (Hallberg, 2006), which provides detailed information on the impact that the different social agents with whom they interact in their daily lives have on the sample.

\section{Methodology}

The sense of belonging is a psycho-social concept influenced by the way in which people perceive and value their relationships and their surrounding environment. Therefore, it was decided to opt for a combination of two qualitative approaches in order to analyse the way in which this process unfolds.

The sample for this study was comprised of 44 Japanese aged between 18 and 66 years (39 women and five men) who during the years 2010 and 2012 resided in Spain, mainly in the regions of Aragon, Catalonia, and Madrid.

During this period, 68 interviews were carried out, as well as a focus group. Data were collected using 
in-depth interviews in sessions of 60-90 minutes. The interviews revolved around three main blocks: (a) pre-migration; (b) settling down process in the host society; and (c) cultural shock and integration strategies.

\section{Coding Variables}

During data analysis, five key variables in developing a sense of belonging by the Japanese community in Spain were identified: (a) presence of Spanish family and friends; (b) interest in some aspects of the host society prior to the settlement phase; (c) work environment; (d) ethnic heterogeneity and use of support networks; and (e) level of Spanish proficiency.

These key elements were evaluated on a 5-point scale, giving a value of 5 to those variables that respondents felt aroused in them a sense of belonging more akin to the culture or society of destination, and 1 to those variables identified with a greater sense of belonging to the country of origin.

\section{Spanish Partners or Friends}

Among the research participants, there was a widespread idea that foreigners who come to Spain without knowing a Spaniard, or who do not have the opportunity to build relationships with people in the area, are at a disadvantage because they have more difficulties in finding a work or training. For this reason, much of the sample considered it necessary to contact Spaniards (in Japan) who could help them improve their language proficiency (oral and comprehension) and at the same time direct or advise them on everyday aspects, such as the use of public transport, operation of automatic teller machines (ATMs) or phone companies, among others.

The informants identified an average of four Spaniards in their social networks before emigrating. For them, having a partner or friend from abroad accentuates the feeling of belonging to the society of destiny as they felt their role was to guide and teach Japanese culture.

Among the interviewees, the number of Japanese who begun a relationship with a Spaniard or a foreigner in Spain increased by 55\% compared to those Japanese who were already in a mixed relationship before emigrating. Similarly, the number of Spaniards identified in social networks increased from four to 15 . However, despite an increase in the number of local inhabitants, the feeling of belonging to the society of origin did not decrease, but rather it was reinforced.

As discussed in the focus group, one of the reasons behind this situation is the difference in social patterns and norms between both cultures. Taro, a Japanese, married for four years with a Spanish woman, stated his case as follows:

In Japan, I had already studied a lot about Spanish traditions, festivals, and customs, but to live, the experience is very different. Making new friends was easy thanks to my wife and family, and that has made a lot of things easier for me, so I am very grateful, but although I am more than happy to be in Spain, there are things that I just cannot understand and that makes me feel more Japanese than before. For example, my wife's relationship with her mother is very strong. They spend the day together, and sometimes I do not know if she cares more about her mother than for me and our children. Another example is when we celebrate Spanish holidays, such as Christmas or Easter. When many people come to our home to visit us, or we go to the home or family of our friends, sometimes I feel I will never integrate into Spanish culture. Although I have a good time, there are a lot of jokes and other things I cannot understand and no one is capable of explaining them to me. So, I feel a bit sad and, although I like this country and its people, I think that there are things that I cannot understand because I am Japanese.

\section{Interest on Some Aspects of the Host Society}

In February 2013, the Japanese Ambassador to Spain, Mr. Satoru Sato, when participating in conferences on "Japan in a global world", stated that "In recent years, Spain has become fashionable in Japan". Whilst it is 
true that the number of Japanese interested in Spain has increased in recent years, it is also necessary to know the reasons for the rise in popularity of Spanish culture in the Japanese archipelago.

The attraction elements presented by Spanish society are many, dancing, painting, and architecture being the most outstanding. The media plays a key role in projecting the image of the host society. According to the participants in this research, the two main reasons promoted by the media for emigrating to Spain are the friendliness and charm of the Spanish (71\% of the sample) and a laid-back lifestyle (65\%).

Regardless of personal interests and the opportunities that the host society offers, learning the Spanish language is very important for the Japanese. About seven out of 10 of the participants claimed that before considering the possibility of emigrating, having a hobby related to Spanish culture did not mean they were interested in learning the language, because much of the material involved could be found in their native tongue. However, as interest and the option of migration increased, expanding their knowledge of Spanish acted as an incentive and a source of motivation.

Yoshi, who was a resident in Spain for two years, associates the interest in culture and the need to learn Spanish with a sense of belonging to the host society in following way:

I have always loved Spanish cuisine and have always cooked Spanish dishes for my friends in Japan ... Before deciding to emigrate to Barcelona, I had travelled to Spain a couple of times, and I felt very comfortable here and really enjoyed life in Spain . But when I considered the option of coming to live here, I thought that no matter how well I can cook, and even though I may cook better than some of the Spanish, if I cannot talk to them, I will never be able to learn anything else. Also, there is another thing, even if you do everything you can to show your interest in the culture of a place and want to be part of it, if you cannot communicate with people, you will never experience and understand what is going on. You can only say you have ideas or impressions about something, but you never get to know what it is to be part of that society.

\section{Work Environment}

Apart from the difficulties immigrants have in entering the labour market, they also have to face the problems posed by the homologation of diplomas and academic qualifications. This has forced many Japanese to use their cultural heritage as a means of subsistence in the host society. In other words, with the increasing popularity of Japanese culture in Spain over the last decades, more and more Japanese, unable to certify training undertaken in their country of origin, have chosen to give classes related to different aspects of Japanese culture, such as language, flower arrangements, calligraphy, etc..

For much of the sample, this has had a huge impact on the development of both the sense of belonging and their national identity. As Ahnellen et al. proposed (2006), one of the bases that makes an individual feel part of a group is that the group values his/her involvement and contributions. From this perspective, diffusion and transmission of the culture of origin in the host society has a dual function. On the one hand, it acts as a gateway and a way of making ties with the native population; and on the other hand, it serves to consider certain cultural aspects in depth and later share them with others, thus, allowing the members of this community to understand and adopt certain values that help reaffirm their national identity and their sense of belonging.

Maya, a graduate in English Philology in Japan and a professor of "origami" (paper folding), describes the situation as follows:

When I came to Spain, nobody wanted to employ me as an English teacher, because I could not prove my qualifications, but on the other hand, I could teach Japanese without any qualifications. At first, I could not understand this, and in fact, I did not want to teach the Japanese language because this meant I would have to study it again. One day, a friend told me that they were looking for someone Japanese for an origami workshop, and because I was very fond of it 
when I was young, I applied.... I have been in Spain for four years now and my work has always been related to Japanese culture. To be honest, when I was in Japan, I thought that this was just an old fashioned silly thing, but now, thanks to "these silly things", I have been able to make a lot of Spanish friends and understand my own culture better.

\section{Ethnic Heterogeneity and Function in Support Networks}

In the field of migration, informal support is considered the most important form of support, especially in the early stages of settlement (Maya, 2002; 2004), as it is much more accessible than that offered by official institutions, such as embassies, police, or social services in general.

As the migration project presented by the Japanese community is partly based on cultural aspects of the country of origin, it favours the creation of social and support networks made up of Spaniards. Likewise, their minority status hinders the creation of ethnic enclaves and fosters relationships with other immigrants with whom they share their foreign status and/or personal interests.

One of the most important aspects when analysing support networks is to know how these groups are formed. In the case of the Japanese community, two mechanisms have been identified. Firstly, having a Spanish partner not only opens the door to the host society, but also helps establish first contact with the native population. Secondly, attending Spanish courses or other recreational activities contributes to the incorporation of both Spaniards and other immigrants in their support networks.

However, as noted by the informants, not all support networks have the same functions. For example, a partner or other Spaniards are considered sources of functional support; that is to say, the help perceived and expected of them is designed to address issues related to understanding social patterns and behaviour or how society, public bodies, and other institutions work. On the other hand, the support given by Japanese and other foreigners, especially from those considered akin from a cultural point of view (e.g., Korean or Chinese), is usually affective, because, as mentioned by the informants themselves, sometimes it is easier to empathize with others who are in a similar situation.

It is worth noting that, within the Japanese group, women show a greater degree of satisfaction with their migration experience. The information obtained suggests that the role of women in the society of origin makes it difficult to achieve personal goals, quite the contrary to the characteristics of Spanish society which offers them a higher degree of freedom that allows them to combine different activities without having to give any of them up. Akane, who has been working in Spain for a Japanese company since 2010, compared her experiences working in both countries as following:

Now, I do the same work as in Japan. I am the boss's secretary, but here I do my day's work and then I can go home or wherever, but in Japan, there is nothing like a "working day". In Tokyo, I could work 10 or 11 hours in the office, but then, if my boss needed anything, he called me at home and I had to comply ... He even asked for things unrelated to work, such as buying online, and so on. This situation annoyed me, but all my friends and my family said it was normal, so ...

\section{Level of Spanish Proficiency}

As Lueck and Wilson (2010) suggested, the degree of proficiency in the language of the host society could be considered one of the most reliable indicators of the level of integration, especially when the source and destination languages differ so much, as is the case of Japanese and Spanish.

The study of the Spanish language is a priority of the Japanese migration project. Approximately seven out of 10 respondents had studied Spanish in Japan, and $76 \%$ of these continued studying for an average of two years after arriving in Spain. 
However, for most interviewees, learning Spanish was not perceived as an end in itself but as a tool. As discussed in section "Interest on Some Aspects of the Host Society", Spain was chosen as a destination because it aroused certain interest in some cultural or social aspect. However, similarity between the phonetic systems of both languages has led the Japanese to identify more readily with the Spanish language rather than with other more widespread European languages, such as English, French, or German.

\section{Conclusions and Recommendations}

The results obtained in this study suggest that among the Japanese community in Spain, there is a direct relationship between the composition of multiethnic social networks and the favorable development of a feeling of belonging to the host society.

Firstly, during the post-migration phase, the respondents reported feeling somewhat identified with Spanish culture. In this sense, the social imaginary promoted by the media (television, Internet, or printed media) along with discontent or rejection of certain aspects of the society of origin (social pressure, lack of freedom, etc.) help generate a positive image of the host society.

In the case of the Japanese group, having a high foreign language proficiency helps strengthen the feeling of belonging to Spanish society. As the respondents commented, during the 1970s and 1980s, Spanish was a minority language among Japanese students, therefore, being able to communicate in a language other than Japanese or English distinguished them from other peers. Furthermore, the ability to speak Spanish links them with second- and third- generation Japanese who emigrated to Latin American countries, such as Bolivia or Peru, and with immigrants from South American and Spain.

Secondly, the social imaginary is reinforced by a personal interest in migrating to a particular area. Unlike other groups whose immigration objective and destination are determined by parameters, such as the economic development of a given area or the ability to access a particular sector of the labour market, the choice made by cultural immigrants to settle in a given area is based on other criteria, such as training opportunities or places where leisure time activities tie in with their interests in local culture.

The combination of these two variables (social imaginary and interest in the host society's culture), undoubtedly contributes in adopting a favourable attitude when creating new social networks in the country of destination. Also, the interest in Japanese culture in Spain also helps promote smooth relations between members of both groups.

According to Vaux (1990), the meta-concept of social support includes basic aspects, such as belonging, involvement, and commitment. Therefore, with respect to the sense of belonging to the host society, the participants in this research considered that they could fulfil the objectives set during the post-migration phase, and that having the opportunity to establish multiethnic networks has encouraged the development of a greater feeling of belonging to the host society. Thus, the participation of interviewees in cultural activities involves both these key elements (migration objectives and the creation of multiethnic social networks).

As mentioned during the discussion group, although there is an increasing awareness of Spanish culture in Japan, there are few leisure time or training facilities available, either formally or informally, in this field. Therefore, this makes it difficult to find people who share these interests. Thus, for example, through Spanish language courses for foreigners, participants were able to establish networks with people from other cultures with whom they could share both their interest in the language and culture as well as their experiences during the settlement phase. The social networks that members of this group were able to establish in Spain allowed 
them to feel an active part of the host society, and this has led to the development of a sense of belonging to the place of destination.

However, the results also show that within the Japanese community in Spain, there is a clear distinction between the sense of belonging and national identity. Although the results point to a strong sense of belonging to the host society, it has also identified a very well defined Japanese national identity.

Regarding the identity process, interrelation in multiethnic networks promotes an awareness of one's national identity. Encountering a different culture also favours finding the meaning of one's own culture through the exercise of distance and contrast. This assessment is not without conflict. Despite the harmonious coexistence of a sense of belonging to Spanish society and the sense of Japanese national identity, research carried out by Green (2008) and Machimura (2003) mentioned certain difficulties in the assimilation of national identity within the two most relevant phenomena of Japanese migration found in literature (the Latin American and North American cases) which are characterised by a low level of involvement in multiethnic networks and a poor sense of belonging to the host society.

This undoubtedly opens up new questions aimed at understanding the reasons why the Japanese in Spain tend to break this trend. Likewise, it would be necessary to carry out comparative studies between the Japanese communities in different European countries in order to see if this new trend of "cultural immigration" is creating a new model of the Japanese community in Europe.

In order to identify the impact of multiethnic social networks and the new feelings of belonging that are emerging in Spain, it is necessary to establish links between the different social agents that make them up. This will help us understand how, why, and where these changes are leading us. De Miguel and Tranmer (2010) warned that the trend in Spain to carry out research in the field of migration, focussing exclusively on immigrant groups as isolated entities within the host society, may project the image of a dual society in which immigration exists, but with which one does not live. This biased and atomistic view of social reality may create an elite national identity that challenges realities, such as mixed marriages or coexistence in multicultural spaces, considering them isolated phenomena that have no effect on the development of Spain.

\section{References}

Ahnellen, J., Suyemoto, L. K., \& Carter, S. A. (2006). Relationship between physical appearance, sense of belonging and exclusion and racial/ethnic self-identification among multicultural Japanese European Americans. Cultural Diversity and Ethnic Minority Psychology, 12(4), 673-686.

Ariza, M. (2002). Migration, family and transnationality in the globalization context: Some reflections. Revista Mexicana De Sociologia, 64(4), 53-84.

Ashikari, M. (2003). The memories of the women's white face: Japaneseness and the ideal image of women. Japan Forum, 15(1), 55-79.

Beltrán, J. (2005). Las comunidades asiáticas en España: Una visión panorámica (Asian communities in Spain: An overview). Revista CIDOB d'Afers Internacionals, 68, 33-51.

Bronfenbrenner, U. (1976). The ecology of human development: History and perspective. Psychologia Wychowawcza, 19(5), 537-549.

Burgess, C. (2012). Maintaining identities discourses of homogeneity in a rapidly globalizing Japan. Retrieved January 19, 2012 , from http://www.japanesestudies.org.uk/articles/Burgess.html\#Author

Camarero Rioja, L. A., \& García Borrego, I. (2004). Los paisajes familiares de la inmigración (Overview of migrant families). Revista Española De Sociología, 4, 173-198.

De Miguel, V., \& Tranmer, M. (2010). Personal support networks of immigrants to Spain: A multilevel analysis. Social Networks, $32(4), 253-262$. 
Fujita, Y. (2009). Cultural migrants from Japan: Youth, media and migration in New York and London. Plymouth, U.K.: Lexington Books.

Goodman, R., Peach, C., Ayumi, T., \& White, P. (2003). Global Japan: The experience of Japan's new immigrant and overseas communities. London: Routledge Cruzon.

Green, P. (2008). Family and nation: Brazilian national ideology as contested transnational practice in Japan. Global Network, $8(4), 418-435$.

Gualda Caballero, M. E. (2008). Identidades, autoidentificaciones territoriales y redes sociales de adolescentes y jóvenes inmigrantes (Identities, territorial self-identifications and social networks of adolescents and young immigrants). Portularia: Revista De Trabajo Social, 8, 111-129.

Hallberg, R. M. L. (2006). The "core category" of grounded theory: Making constant comparisons. International Journal of Qualitative Studies on Health and Well-Being, 3(1), 141-148.

Lueck, K., \& Wilson, M. (2010). Acculturative stress in Asian immigrants: The impact of social and linguistic factors. International Journal of Intercultural Relations, 34(1), 47-57.

Machimura, T. (2003). Living in a transnational community within a multi-ethinc city. Making a localised "Japan" in Los Angeles. In R. Goodman, C. Peach, A. Takenaka, and P. White (Eds.), Global Japan: The experience of Japan's new immigrant and overseas communities (pp. 147-156). London: Routledge Cruzon.

Magat, N. I. (1999). Israeli and Japanese immigrants to Canada: Home, belonging, and the territorialization of identity. Ethnos, 27(2), 119-144.

Martínez-Callaghan, J., \& Gil-Lacruz, M. (2011). Redes de sociales y sentimiento de pertenencia en el colectivo inmigrante japonés en España (Social networks and sense of belongning among in the Japanese immigrant community in Spain). In Memo of the VIII International Congress on Migration in Spain: Human Mobility and Social Diversity (pp. 1-15), Bilbao.

Maya, I. (2002). Estrategias de entrenamiento de las habilidades de comunicación intercultural (Training strategies of intercultural communication skills). Revista de Trabajo Social, 2, 91- 108.

Maya, I. (2004). La formación de comunidades de inmigrantes: Desplazamiento en cadena y contexto de recepción (The formation of immigrant communities: Displacement chain and reception context). Revista Iberoamericana de Filosofia, Politica y Humanidades, 6(12), 83-91.

Ono, H., \& Piper, N. (2004). Japanese woman studying abroad the case of USA. Womens Study International Forum, 27, 101-118.

Rindfuss, R. R., Bumpass, L., Choe Kim, M., \& Tsuya, O. N. (2004). Social networks and family changes in Japan. American Sociology Review, 69, 838-861.

Sakai, C. (2003). The Japanese community in Hong Kong in the 1990s. The diversity of strategies and intentions. In R. Goodman, C. Peach, A. Takenaka, and P. White (Eds.), Global Japan: The experience of Japan's new immigrants and overseas communities (pp. 131-146). Londres: Routledge Cruzon.

Sasaki, M. (2004). Globalization and national identity in Japan. International Journal of Japanese Sociology, 13, 69-86.

Suzuki, T. (2006). Becoming "Japanese" in Bolivia: Okinawan-bolivian trans (national) formations in colonial Okinawa. Identities: Global Studies in Culture and Power, 13, 455-481.

Takamori, A. (2010). Rethinking Japanese American "heritage" in the homeland. Critical Asian Studies, 42(2), $217-238$.

Vaux, A. (1990). Ecological approach to understanding and facilitation social support. Journal of Social Support and Personal Relationships, 7, 507-518.

White, P., Hwa-Seo, P., \& Pieke, N. F. (2006). Las diásporas de Asia oriental en Europa occidental (East Asian diaspora in Western Europe). Barcelona: CIDOB. 